\title{
INDEPENDÊNCIA, PODER JUDICIÁRIO E MINISTÉRIO PÚBLICO
}

\author{
Fábio Kerche*
}

\begin{abstract}
Os estudos acadêmicos sobre a questão da independência do Poder Judiciário e dos juízes, tanto do ponto de vista normativo quanto descritivo, são razoavelmente desenvolvidos. A produção é significativa e discute os dilemas e as dificuldades da existência de um Poder de Estado com altas doses de autonomia em regimes democráticos. Do ponto de vista da democracia, a questão é como atores pouco accountable convivem em um sistema baseado fundamentalmente no voto dos cidadãos. Em relação a esse debate, menor atenção é dada ao Ministério Público e aos promotores. Este ensaio bibliográfico analisa, sintetiza e reinterpreta parte da produção acadêmica sobre independência e suas tensões na democracia em relação ao Poder Judiciário e apresenta uma proposta de como estudar o mesmo tema em relação ao Ministério Público.

Palavras-chave: Poder Judiciário. Ministério Público. Independência. Democracia.
\end{abstract}

\section{INTRODUÇÃO}

Os estudos sobre o Poder Judiciário, de maneira geral, e sobre a questão da independência dos juízes, de maneira específica, tanto do ponto de vista normativo quanto descritivo, são razoavelmente desenvolvidos, embora em número menor do que os relativos à "política stricto sensu". Diversas pesquisas, em especial aquelas realizadas nas universidades norte-americanas, discutem os dilemas e as dificuldades da existência de um Poder de Estado com altas doses de autonomia em regimes democráticos. De uma forma ou outra, praticamente todos tocam na questão de como atores pouco accountable convivem em um sistema baseado fundamentalmente no voto dos cidadãos.

Menor atenção é dada às agências responsáveis pela ação penal nas democracias, que chamarei aqui de Ministério Público. ${ }^{1} \mathrm{O}$

* Fundação Casa de Rui Barbosa, Rio de Janeiro

Rua: São Clemente, 134, Sala L, Botafogo. Cep: 22260000. Rio de Janeiro - Rio de Janeiro - Brasil. fabio.kerche@rb. gov.br; fkerche@gmail.com

1 "Ministério Público" é adotado, entre outros países, por França, Itália, Portugal e Brasil. No Canadá, a instituição é chamada de Public Prosecution Service e, na Inglaterra, de Crown Prosecution Service. Nos Estados Unidos, em nível federal, é o US Attorneys' Office e, em nível local, District Attorney's Office (Cf. Fionda, 1995). número de pesquisas sobre promotores ${ }^{2}$ é significativamente reduzido quando comparado aos trabalhos sobre juízes. Esse menor interesse acadêmico não é proporcional à importância da instituição que seleciona boa parte do que será decidido pelo Poder Judiciário. Nas palavras de um ex-ministro da justiça, procurador-geral e ex-ministro da Suprema Corte dos Estados Unidos, Robert Jackson,

[O] promotor tem mais controle sobre a vida, liberdade e reputação que qualquer outra pessoa nos Estados Unidos. Sua discricionariedade é tremenda [...] Com a legislação preenchida com grande variedade de crimes, um promotor tem uma grande chance de encontrar ao menos uma violação técnica de algum ato da parte de quase qualquer um. Neste caso, não é uma questão de descobrir a responsabilidade em um crime e então procurar pelo homem que o cometeu, a questão é escolher um homem e procurar na legislação, ou colocar investigadores para trabalhar, para colar nele algum delito ${ }^{3}$ (Fleissner, 1997-1998, p. 430-431).

Enquanto, para o Poder Judiciário, é

2 Independentemente de outros nomes atribuídos aos membros do Ministério Público nas democracias (procurador, district attorney etc.), tratarei todos os responsáveis pela ação penal pelo título de promotor.

${ }^{3}$ Todas as citações em que não há uma versão em português foram traduzidas pelo autor deste texto. 
possível apresentar uma discussão sobre a questão da independência baseando-se quase exclusivamente na literatura especializada sobre juízes e em instrumental teórico e empírico desenvolvido especificamente para entender as particularidades desse Poder, em relação ao Ministério Público é necessário "emprestar" ferramentas dos estudos sobre o Judiciário, sobre a burocracia e sobre os políticos. Deve-se parte disso à falta de consenso de que a independência também é necessária para promotores, pelo menos no mesmo grau do que se entende necessária para juízes.

A proposta deste ensaio bibliográfico é dupla: primeiro, fazer uma síntese do debate sobre a questão da independência nas democracias em relação ao Poder Judiciário e, segundo, apresentar uma proposta de como estudar a mesma questão em relação ao Ministério Público.

\section{PODER JUDICIÁRIO E INDEPEN- DÊNCIA}

A democracia não é somente o sistema em que as decisões são tomadas, direta ou indiretamente, pela maioria dos cidadãos. Nas sociedades contemporâneas, a democracia também é o sistema em que certos direitos pre$\infty$ cisam ser assegurados para indivíduos e minoจ rias, mesmo frente ao desejo de maiorias conป junturais. Em outras palavras, a democracia contemporânea é, na verdade, o encontro de duas tradições que nascem separadamente na história e que se relacionam de maneira complexa e desigual entre os países que vivem sob seus princípios: a democracia, com sua lógica majoritária, e o liberalismo político, calcado em direitos (Cf. Bobbio, 1988).

A organização dos Estados democrático-liberais reflete essas duas tradições. Por um lado, os Poderes Executivo e Legislativo baseiam sua atuação primordialmente nos procedimentos majoritários. Não somente porque decisões são tomadas por maioria no parlamento, como pelo axioma de que todos os polí- ticos atuam com vistas a agradar eleitores justamente porque buscam votos para continuar na atividade política. Por outro, o Judiciário é o Poder contramajoritário, cabendo aos juízes o papel de garantidor de direitos individuais e da sociedade, geralmente previstos em documentos como a constituição, mesmo que isso seja contrário a maiorias conjunturais.

Para que esse papel de guardião de direitos seja efetivo, é bastante comum, na literatura, a prescrição, que sempre envolve alguma normatividade, de que é necessário um grau razoável de independência do Poder Judiciário frente aos outros atores. "Judiciários independentes estão melhor situados que suas contrapartes menos independentes para fazer valer [enforce] direitos constitucionais contrários às maiorias populares e, dessa forma, corrigir injustiças detectadas” (Clark, 2011, p. 264). Assim, é um “consenso normativo” (Melton; Ginburg, 2014, p. 187), um "estereótipo normativo" (Maravall, 2003, p. 264) ou um "conceito quase religioso" (Taylor, 2017, p. 5) que independência é necessária e essencial para que os juízes resolvam disputas (Cf. Shapiro, 2013). Mesmo que independência não seja um "valor supremo" - já que também são importantes consistência, precisão, previsibilidade e rapidez das decisões -, é inegável que é "um importante componente em muitas definições de qualidade da Justiça” (Melton; Ginburg, 2014, p. 190).

A definição de independência tem pequenas variações de amplitude, embora todas digam respeito a atores externos à instituição e "conexões - ou, mais precisamente, ausência de certas conexões" (Russell, 2001, p. 2). O Poder Judiciário é independente quando detém a "habilidade para tomar decisões que não são afetadas por pressão política de fora do Judiciário" (Clark, 2011, p. 5), quando "decide casos à luz da lei sem considerar as indevidas opiniões de outros atores governamentais" (Melton; Ginburg, 2014, p. 190), ou quando “decisões judiciais não podem ser anuladas por legislação retroativa ou por recursos para 
o parlamento ou o governo" (Maravall, 2003, p. 266). ${ }^{4}$

Mas não é somente o Poder Judiciário como um todo que deveria ser protegido de ingerências externas de outras instituições ou grupos (Cf. Ferejohn, 1999). O juiz, para exercer seu dever público, deve ser "independente de consideração venal ou ideológica" (Ferejohn, 1999, p. 353). Isso seria facilitado quando o juiz é protegido por instrumentos como inamovibilidade, não redução de salários, estabilidade etc. ${ }^{5}$ A questão, não totalmente resolvida, é se a independência de jure, prevista constitucionalmente, reforça ou garante a independência de facto. ${ }^{6}$

Se o pressuposto madisoniano de que os homens não são anjos é aceito de maneira geral pelos teóricos da democracia, os juízes independentes serem protegidos da accountability dos cidadãos é uma ponta que não se encaixa facilmente no modelo de democracia contemporânea, podendo ser descrita como um "paradoxo da independência - accountability" (Shapiro, 2013, p. 264): ${ }^{7}$

Independência judicial é tanto um problema quanto uma solução. A principal tarefa dos juízes é resolver disputas. Independência é essencial para o sucesso dessa missão. Juízes, entretanto, não apenas resolvem disputas. Tribunais judiciais são 'tribunais da lei' que resolvem disputas de acordo com a lei. Quaisquer intérpretes da lei ou que digam o que um

${ }^{4}$ Taylor inclui também variáveis internas para a independência. Segundo ele, há a "independência externa”, em relacão a atores de fora do Poder Judiciário; a "autonomia", relativa à liberdade administrativa do Judiciário; e a "independência interna”, "o grau com que cada juiz individual ou tribunais de instâncias baixas podem ficar constrangidos pela revisão dos altos tribunais" (Cf. Taylor, 2017, p. 1).

${ }^{5}$ Melton e Ginburg buscam identificar se a independência de jure, prevista na lei, reforça a independência de facto, na prática. "Nossos resultados sugerem que a independência judicial de facto pode ser incrementada se países adotarem procedimentos de seleção e de remoção que insulem os juízes de outros Poderes do Estado" (Melton Ginburg, 2014, p. 210).

${ }^{6}$ Vários trabalhos buscam medir a independência de facto nas democracias. O mais conhecido é o grande levantamento feito por Linzer e Staton (2015).

${ }^{7}$ Independência é sempre uma questão delicada para a teoria democrática, não somente em relação ao Poder Judiciário. Bancos Centrais independentes, agências reguladoras, burocracia, Mistério Público (que será visto na segunda parte deste ensaio bibliográfico) etc. são instituições em que os dilemas da accountability e da democracia também ocorrem. texto legal significa, em algum grau, em algum momento, e sob algumas circunstâncias, fazem a lei. Se juízes fazem a lei, eles não devem ser independentes de forma absoluta. Eles devem ser accountable por alguém (Shapiro, 2013, p. 253-254).

Há um razoável grau de concordância de que existe uma tensão, uma "dificuldade contramajoritária” (Bickel, 1986, p. 16) entre os princípios liberais, representados pelo Judiciário, e a democracia, que prevê que atores com discricionariedade sejam accountable, uma "premissa fundamental da democracia liberal" (Seidman, 1987-1988, p. 1571). Na verdade, "a realidade essencial [é] que a revisão judicial é uma instituição desviante na democracia norte-americana” (Bickel, 1986, p. 18), mas não somente nesse país. "Quis custodiet ipsos custodies [quem guarda os guardiões] é o ponto fraco no papel atribuído ao rule of law na teoria democrática liberal” (Maravall, 2003, p. 266). E a questão fica mais delicada quanto mais alto é o tribunal em análise, em especial para casos de revisão constitucional (Cf. Shapiro, 2013). Isso porque "[...] constituições tendem a ser ainda mais genericamente escritas que leis ordinárias, juízes comprometidos com a interpretação constitucional têm maior probabilidade de exercer grandes poderes para fazer leis" (Shapiro, 2013, p. 258). Por isso, nos tribunais responsáveis primordialmente pelo controle constitucional, em que os juízes são apenas accountable por meio de impeachment e que legisladores somente podem corrigir as decisões desses juízes por meio de mudanças baseadas em maiorias qualificadas e em longos processos legislativos, a "accountability parece ser muito fraca” (Shapiro, 2013, p. 268).

Os instrumentos institucionais que garantem autonomia aos juízes são, entre outros, a constitucionalização das garantias do Poder Judiciário (dificultando mudanças da legislação pelo parlamento), a estabilidade no trabalho, a proteção em relação a remoções e salários (Cf. Melton; Ginburg, 2014). Em suma, são "garantias corporativas" (Maravall, 2003, p. 268). Esses instrumentos insulariam os juízes 
e garantiriam que eles não ficariam submetidos aos desejos dos políticos ou das maiorias conjunturais.

Existem três tipos de explicações para a independência do Poder Judiciário, pelo menos nos Estados Unidos, e todas elas possuem suas limitações (Cf. Seidman, 1987- 1988). A primeira tentativa seria a explicação "originalista”, em que a independência seria um substituto da accountability, porque se sustenta no texto constitucional que expressa o desejo dos "pais fundadores" e somente isso bastaria para legitimar as decisões judiciais e limitar o papel dos juízes. Embora não seja exatamente a mesma abordagem, é bastante semelhante ao que Ferejohn (1999) chama de explicação "histórica”. Segundo ele, o Poder Judiciário é independente porque na sua criação essa solução respondia a "conflitos políticos específicos" (Ferejohn, 1999, p. 376). O problema, óbvio, é que, sem a accountability, não há garantias de que os juízes respeitarão a constituição.

A segunda explicação seria a "teoria baseada em direitos”, uma espécie de complementação normativa à teoria originalista. Nessa explicação de tipo contratualista, a independência é a melhor opção, porque seria aquela escolhida por participantes desinteressados da comunidade. Por essa explicação, “juízes, livres das obrigações políticas, poderiam ser ¿ें objetivos e desinteressados. Mas, certamente, Фं a conclusão oposta é igualmente plausível” (Seidman, 1987-1988, p. 1581).

¿ E, finalmente, existe a explicação da "teoria majoritária”, em que a independência do Poder Judiciário é justificada porque a maioria prefere que certas questóes, como as relativas à constituição, sejam decididas pelo Poder Judiciário. "Este argumento confunde o exemplo da delegação com o exemplo da ausência da accountability" (Seidman, 1987-1988, p. 1586). Ou, para usar outros termos, confunde "abdicação" com o que seria um caso para "delegação". ${ }^{8}$

${ }^{8}$ Nem toda a delegação de tarefas e poderes dos políticos para uma instituição não eleita é uma abdicação (Cf.
A solução teórica para justificar a questão da independência, contudo, passa, de alguma forma, pela sempre lembrada afirmação de que o Judiciário é o Poder "menos perigoso para os direitos políticos da constituição", como escreveu Hamilton no texto Federalista n. 78 (Madison; Hamilton; Jay, [1788] 1993, p. 479). Ou seja, a independência, na democracia liberal, somente faz sentido se vier acompanhada da ideia de que a autonomia não é contrária à própria democracia, porque os juízes "não têm, estritamente, força nem vontade, mas tão somente julgamento, estando, em última instância, na dependência do auxílio do braço executivo até para a eficácia de seus julgamentos" (Madison; Hamilton; Jay, [1788] 1993, p. 479). Ou, dito de outro modo,

Já que os teóricos liberais tratam a democracia como axiomática, há uma tendência natural para tentar demonstrar que as decisões judiciais são, em algum sentido, compatíveis com a democracia. Mas, na medida em que esse esforço é bem-sucedido, ele marginaliza a importância do Judiciário e rebaixa o argumento que é crucial para nosso sistema de governo (Seidman, 1987-1988, p. 1573).

Assim, a independência do Poder Judiciário seria justificada porque ele é frágil relativamente aos outros Poderes - esses, sim, fortes e que precisam ser limitados pela vigília dos eleitores e dos próprios juízes. Ao serem frágeis e dependentes, a necessidade da accountability para o Poder Judiciário seria menos eminente.

A questão é que não é mais verdade que o poder de julgar é "invisível e nulo" (Montesquieu, [1748] 1973, p. 157) nas democracias contemporâneas. Entre outras coisas, porque, ao interpretar as leis, um juiz "faz lei" (Shapiro, 2013, p. 254). Depois, porque os políticos levam em consideração os tribunais em suas estratégias (Cf. Maravall, 2003). Além disso,

McCubbins; Noble, 1995). Caso haja algum tipo de controle orçamentário e (ou) os políticos mantenham algum instrumento institucional que gere incentivos para determinados comportamentos por parte dos atores não eleitos, mesmo que indiretos, a relaçấo não poderia ser classificada como uma abdicação. Esssa definição, entretanto, é muito extrema e não capta fenômenos intermediários (Cf. Kerche, 2009). 
"os grupos de interesse procuram o local institucional mais favorável para contestar políticas públicas (venu-seeking)" (Taylor, 2007, p. 234) e o Poder Judiciário é, muitas vezes, uma das arenas escolhidas. A independência, na verdade, é melhor representada por um continuum com diversas gradações. Num extremo, o Judiciário subserviente, totalmente subordinado à pressão política; no outro, juízes imperiais, completamente distantes de qualquer constrangimento externo ao Poder Judiciário (Cf. Clark, 2011; Seidman, 1987-1988). ${ }^{9}$ O ponto em que se encontra o Poder Judiciário, contudo, não é único, variando de país para país, em momentos históricos diversos ${ }^{10} \mathrm{e}$, inclusive, entre instâncias de um mesmo sistema de justiça. A dificuldade da análise não se encontra nos extremos, mas na "área cinzenta" (Clark, 2011, p. 7).

Para além da normatividade, é fato que, nas democracias contemporâneas, os juízes e o Poder Judiciário não são totalmente independentes - embora alguns insistam que, se um princípio não pode ser atingido, não deve ser abandonado (Cf. Russell, 2001). Assim como não existe algo que seja a perfeita accountability, porque sempre há espaço para o agent agir sem o controle do principal,"11 "é similarmente impossível conceber um sistema que faça juízes completamente não accountable" (Seidman, 1987-1988, p. 1576)..$^{12} \mathrm{Na}$ verdade,

${ }^{9}$ Segundo Maravall (2003), quanto maior a independência, menor o risco para um juiz que tem suas preferências participar da política.

${ }^{10} \mathrm{Com}$ as democratizações mais recentes, como na América Latina, houve uma aproximação dos modelos da "civil law" com a "common law" do ponto de vista do uso político do Poder Judiciário. Essa mimese, contudo, não teria sido acompanhada de um aumento expressivo da accountability política sobre os juízes (Cf. Maravall, 2003).

${ }^{11} \mathrm{O}$ principal é aquele que delega ao agent uma tarefa. $\mathrm{O}$ exemplo citado por Przeworski (1998a) para ilustrar o modelo é quando se leva um carro para a oficina. O mecânico é o agent e o dono do carro é o principal. O ponto é como incentivar que o agent aja no sentido desejado pelo principal (que o carro seja bem e rapidamente consertado, que o preço seja baixo, que ele use peças novas etc.) sem que o proprietário acompanhe todo o serviço e não conheça nada sobre mecânica de automóveis. Isso se aplica também para político e burocratas, eleitores e políticos.

${ }^{12}$ A accountability é entendida aqui como prestação de contas e capacidade de premiação ou punição por atores externos à instituição. Controles internos, como corregedorias ou hierarquia, nã̃o são instrumentos de accountability político. pelos menos na democracia norte-americana, e muito possivelmente para os demais países democráticos, a dependência do Judiciário em relação "aos Poderes políticos não é um acidente constitucional” (Ferejohn, 1999, p. 362). Esses limites à independência são apresentados pela literatura ora por instrumentos institucionais previstos em legislação e controlados por atores externos ao Poder Judiciário, aqueles típicos procurados por institucionalistas de escolha racional; ora por constrangimentos sociais ou "instituições informais" (Taylor, 2017, p. 3), importantes para a análise do institucionalismo sociológico; e ora por questões históricas, uma espécie de path dependence do institucionalismo histórico.

Em relação aos instrumentos institucionais formais que limitam a independência dos juízes e geram alguma forma de accountability, a literatura aponta para aqueles situados nas mãos dos políticos, como a indicação de juízes (Cf. Ferejohn, 1999), o impeachment, outras formas de remoção e renovação de mandatos (Cf. Seidman, 1987-1988), a possibilidade de mudança na legislação (Cf. Clark, 2011), a execução (enforcement) da decisão do juiz ser realizada pelo governo (Cf. Seidman, 19871988) etc. Em outras palavras, juízes que têm estabilidade podem ser accountable "se nós restringirmos seus poderes" (Seidman, 19871988, p. 1575). Todas essas seriam ferramentas que os políticos, e indiretamente a sociedade, detêm para estimular certos comportamentos e desestimular outros no Poder Judiciário. Os juízes, por saberem disso, balizariam suas decisões de forma a buscar evitar o uso desses instrumentos por atores externos, com vistas a não serem prejudicados, por exemplo, em suas carreiras. Esse tipo de abordagem, chamada de "separação de Poderes", mostra que, em algumas situações, a decisão tomada pelos juízes é diferente da opção original do Poder Judiciário, justamente pela influência de atores externos (Cf. Clark, 2011). "O resultado é que a independência judicial é a consequência da interação entre as preferências do Judiciário e 
dos outros Poderes do Estado" (Taylor, 2017, p. 8). Em termos do neoinstitucionalismo de escolha racional, é dizer que os agents (juízes) se adiantam aos desejos do principal (políticos), buscando não ser punidos.

Enquanto os instrumentos acima são típicos da accountability horizontal, nos Estados Unidos, grande parte dos juízes, e justamente aqueles que decidem a maioria dos casos levados à justiça, são eleitos diretamente pelos cidadãos, em um instrumento típico da accountability vertical. No ano de 1994, 70,5\% dos juízes estaduais foram eleitos em processos baseados em partidos ou candidaturas avulsas (Maravall, 2003). Isso pode ser apontado como o inverso do clássico problema que envolve democracia e Poder Judiciário: no lugar da "dificuldade contramajoritária”, teríamos a "dificuldade majoritária”. A questão passa a ser

como juízes eleitos/accountable podem ser justifica-
dos em um regime comprometido com o constitu-
cionalismo. [...] Juízes que protegem a minoria con-
trária às vontades da maioria, por exemplo, podem
ser derrotados na próxima eleição e substituídos por
juízes mais sintonizados com a vontade majoritária
(Croley, 1995, p. 694).

Portanto, a opinião pública norte-americana, por via direta, e não somente os políticos, detém instrumentos que limitariam a independência dos juízes, modelo que também apresenta desafios à democracia liberal.

Mesmo nos países que não adotam eleições como método de seleção dos integrantes do Poder Judiciário, a opinião pública é um ator que entraria, de forma indireta, no cálculo político dos juízes, justamente porque os † cidadãos estão presentes no cálculo eleitoral dos políticos. No modelo chamado de "autocontenção condicional” [conditional self-restraint], elaborado por Clark (2011) para pensar as instâncias superiores do Poder Judiciário, a Corte precisa do apoio da opinião pública para se legitimar. Essa legitimidade, ou a "reserva de boa vontade" (Clark, 2011, p. 67), permite que, em alguns momentos, a Corte tome decisões impopulares. Um dos indicadores de que pode estar ocorrendo uma perda de apoio popular é a introdução de projetos de lei, no Congresso, contrários aos interesses e ao insulamento do Poder Judiciário. Os políticos, buscando agradar seus eleitores descontentes com os juízes, ameaçariam o Poder Judiciário com mudanças na legislação para frear o ímpeto dos juízes, o que é chamado de "legislação moderadora da corte" ["court-curbing legislation"] pelo autor. "Pesquisa mostra que quando o apoio popular para a [Suprema] Corte diminui, o público vai aumentando o apoio para os esforços de sanções políticas que limitem os poderes formais da Corte" (Clark, 2011, p. 67). ${ }^{13}$

No campo das instituições informais, a literatura aponta que a "ideologia” (Cf. Clark, 2011), o "ideal da lei” (Maravall, 2003, p. 267), o "desejo de ser prezado e admirado" (Burbank; Goldberg, 2002, p. 5), a "vida em comunidade", a "autoimagem" (Cf. Burbank; Friedman, 2002), a "classe social" e questões relativas à "moral” (Cf. Ferejohn, 1999) seriam elementos que serviriam de estímulo para certos comportamentos de juízes e desestimulariam outros, limitando, nesse sentido, a total independência do Poder Judiciário. "De fato, uma vez que o salário e a estabilidade no emprego estão garantidos, ironicamente a porta está aberta para muitos outros fatores para influenciar o comportamento judicial" (Burbank; Friedman, 2002, p. 27). Assim, para além dos instrumentos institucionais formais e localizáveis na legislação, existiriam outros, como

[...] prêmios e penalizações que assumem um caráter mais social do que monetário. A responsabilidade profissional enfatizada, em boa medida, por um sistema de princípios (ética) internalizados durante o processo de educação e reforçados, em alguma medida, por punições formais e, mais amplamente, por reputações (Arrow, 1985, p. 50).

É importante destacar, contudo, que, se os instrumentos não formais fossem suficientes para limitar e moldar comportamentos dos

${ }^{13} \mathrm{O}$ outro modelo apresentado pela literatura é o "atitudinal", em que os juízes levariam em conta, para a tomada de decisão, somente sua própria ideologia (Cf. Clark, 2011; Gilman; Clayton, 1999). 
atores estatais nas democracias, não haveria necessidade de outras formas de controle e, no limite, do próprio processo eleitoral. Levada essa lógica ao extremo, a democracia funcionaria numa espécie de "piloto-automático", para pegar emprestada a expressão de Sutherland (1993). Na verdade, as instituições informais somente fazem sentido quando entendidas como um complemento das instituições formais, aquelas buscadas pelos neoinstitutionalistas de escolha racional.

Outra abordagem é aquela, já descrita neste ensaio bibliográfico, que entende que a independência do Poder Judiciário e seus limites são marcados pelas escolhas originais dos "pais fundadores", ou, em outros termos, por uma "path dependency": "A ideia básica, e enganosamente simples, é que escolhas políticas [policy] feitas quando uma instituição está sendo formada, ou quando a política pública é iniciada, terá uma influência contínua e, em grande parte, determinante sobre a política no futuro" (Peters, 2012, p. 70). As raízes históricas e a tradição, pensadas também como instituições, moldam comportamentos e, portanto, também limitam a independência dos juízes.

Se a independência do Poder Judiciário é limitada em diferentes graus por instrumentos institucionais formais e informais, além das escolhas feitas no passado, há um mecanismo que, se não restringe a independência, limita que um ator pouco accountable tenha total autonomia para se posicionar sobre qualquer assunto, a qualquer momento. Refiro-me à necessidade de que um ator externo provoque um juiz para arbitrar sobre uma questão, já que o Poder Judiciário, com raras exceções, como os juízes de instrução na França, geralmente só age quando acionado por um terceiro. Esse mecanismo permite que o Poder Executivo e, em parte, também o Legislativo, controle uma porção substancial dos atores encarregados de romper a inércia do Judiciário (promotores e advogados do governo, por exemplo), assim como exerça um controle sobre a ação penal e de parcela expressiva das matérias sujeitas à revisão constitucional. O direito de selecionar o que será discutido no âmbito judicial é extremamente importante. Como afirma William West, citando Kenneth Davis, "geralmente as mais importantes decisões discricionárias são as negativas, como não iniciar, não investigar, não processar, não entrar em acordo, e as decisões negativas geralmente significam uma disposição definitiva” (West, 1995, p. 25).

Em suma, não cabe ao Poder Judiciário, com algumas exceções, escolher quais os assuntos que serão decididos pelos - se não totalmente independentes, bastante autônomos - juízes. De certa forma, portanto, são os Poderes políticos que controlam as duas pontas do processo judicial: a entrada, selecionando o que merece a análise dos juízes, e a saída, já que cabe especialmente ao Poder Executivo fazer com que as decisões do Judiciário sejam cumpridas. O instrumento da seleção dos casos apresentados ao Poder Judiciário, relativamente pouco lembrado, tem consequências para o tema de sua independência.

\section{MINISTÉRIO PÚBLICO E INDE- PENDÊNCIA}

Os Estados possuem um órgão encarregado da ação penal, não deixando a missão de processar criminalmente um cidadão na mão de particulares. Geralmente, essa é uma tarefa desempenhada por promotores, mas até a polícia já foi encarregada de apresentar matérias penais para os tribunais em algumas democracias (Cf. Fionda, 1995; Tonry, 2012). Além de poder selecionar os casos que irão ser julgados pelo Poder Judiciário e negociar penas com réus,14 os responsáveis pela ação penal também participam da construção da sentença [sentencing] "por meio da decisão das acusações do indiciamento, tipo de julgamento e assim por diante" (Fionda, 1995, p. 1).

\footnotetext{
${ }^{14}$ Nos Estados Unidos, por exemplo, 95\% das penas são resultados de negociação (plea bargain) entre o promotor e
} $\mathrm{o}$ advogado de defesa (Cf. Tonry, 2012). 
Diferentemente do Poder Judiciário, a organização da agência responsável pela ação penal varia significativamente de país para país. "Polícia, tribunais e sistema correcional são muito parecidos em todos os países desenvolvidos, mas promotorias diferem radicalmente" (Tonry, 2012, p. 1). Mesmo a forma como são chamados os seus integrantes e a denominação do órgão, nos diferentes países democráticos, são diversos, e utilizar promotores e Ministério Público para todos é somente uma “questão de conveniência”, para esse autor.

O Ministério Público e o Poder Judiciário, embora façam parte do sistema de justiça e, em alguns casos, sejam formalmente parte do mesmo Poder de Estado, ${ }^{15}$ têm atribuições diversas. A simples transposição da prescrição normativa da necessidade de independência dos juízes para os promotores, como facilmente se identifica nos debates no Brasil, é equivocada. Atribuições diferentes (investigar, julgar, acusar etc.) demandam graus de independência diversos, embora o paradoxo independência-accountability - que, na verdade, pode ser atribuído para boa parte dos órgãos públicos - também esteja presente para o Ministério Público (Cf. Shapiro, 2013).

Diferentemente do Poder Judiciário, o Ministério Público não é inerte, sendo os pro$\infty$ motores os atores privilegiados para provocar ¿ें os juízes, por poderem escolher as matérias Фं que serão judicializadas. Esse papel de selecionar e priorizar é típico da atividade executiva:

O trabalho da promotoria envolve prioridades e alocação de recursos limitados de forma a otimizar, mas não alcançar plenamente, objetivos públicos ou políticas públicas. Portanto, a decisão de se processar não é totalmente, ou somente, judicial, mas é, em algum grau, executiva. Baseia-se não apenas na percepção de culpa ou inocência do acusado, mas na importância relativa para atingir o controle da criminalidade buscando uma acusação em particular em detrimento de outras. Como uma decisão relativa à alocação de recursos organizacionais é

${ }^{15}$ Os promotores da Suécia, Itália e França são integrantes do Poder Judiciário e suas posições são cambiáveis com as dos juízes. Ou seja, um mesmo indivíduo pode ser juiz e promotor ao longo de sua carreira (Cf. Tonry, 2012). essencialmente executiva, antes que judicial, e porque esses recursos são públicos e voltado para os interesses públicos, eles são essencialmente políticos. Esse é o motivo que os sistemas de common law usam na eleição ou indicação política para promotores (Shapiro, 2013, p. 255).

Por ser, portanto, uma atividade executiva, na maioria dos países, o Ministério Público é ligado ao governo, embora o grau dessa ligação varie entre as democracias. Dessa forma, o debate sobre a questão da independência do Ministério Público permite que se utilize o mesmo instrumental acionado para o estudo das burocracias de maneira geral. Promotores, diferentemente de juízes, são burocratas mais ou menos insulados, a serviço de governos eleitos. E, por ser um órgão de governo, são os políticos que decidem as prioridades da instituição e são accountable politicamente, em última instância, por essas decisões. É do interesse do governo, portanto, que os promotores desempenhem bem suas atribuições com vistas a agradar seus eleitores. Esse modelo, obviamente, também apresenta vantagens e desvantagens. Mesmo se referindo ao caso do Ministério Público Federal dos Estados Unidos [U.S. Attorney's Office], Fleissner sintetiza alguns dos dilemas:

Se o poder é investido no Procurador-Geral [Attor-
ney General], há o risco que o poder seja abusivo
quando a administração [o próprio governo] inves-
tigar alegações contra o presidente ou outro funcio-
nário de alto escalão. Este risco envolve a adminis-
tração receber um tratamento favorável do promotor
que trabalha em um conflito de interesses. Por outro
lado, se o poder é investido em um promotor inde-
pendente, há o risco de que o poder seja abusado
por um promotor excessivamente agressivo, que não
presta contas e possivelmente [seja] politicamente
motivado. Este risco envolve o uso inapropriado por
um promotor não accountable do poder de investi-
gar e indiciar (Fleissner, 1987-1988, p. 428).

Por outro lado, a atuação dos promotores "garante a passividade do sistema judicial, isto é, a falta de iniciativa do Judiciário [self star], permitindo que o ambiente político regule, em alguma medida, as demandas para que o Judi- 
ciário atue" (Guarnieri, 1995, p. 244). Dito de outra forma, o governo eleito, em última instância, filtra e seleciona os casos que devem ser decididos por juízes não accountable, servindo de "guardião", ou "porteiro" [gatekeeper], do Poder Judiciário (Cf. Aaken; Feld; Voigt, 2010). Se os juízes não podem ser facilmente responsabilizados por suas decisões, o governo, por sua vez, é responsável pelo fluxo de ações criminais que chegam ao Judiciário e é accountable pelas decisões tomadas em relação às escolhas que orientam a atuação dos promotores.

Em suma, o governo é o principal e os promotores são os agents, com todos os problemas típicos dessa relação. O principal delega ao agent parte importante da execução da política criminal do país. "Como é impossível formular leis que especifiquem todas as ações dos agents sob todas as contingências, as agências executivas e administrativas conservam um espaço considerável de autonomia para decidir" (Przeworski, 1998b, p. 53, destaque do autor).

Aos moldes de outras delegações para burocracias - delegações que são inevitáveis por conta da grande quantidade de funções do Estado (Cf. Przeworski, 1998a) e mesmo desejáveis (Cf. Kiewiet; McCubbins, 1991) -, há, na relação entre governo e Ministério Público, o tradicional problema do "conflito de interesses" e da "assimetria de informações". O conflito se dá quando os interesses dos promotores não são coincidentes com os dos políticos que fazem parte do governo. Promotores, assim como burocratas, podem ter preferências políticas diversas do principal: priorizar estratégias individualistas para a construção de suas carreiras (Cf. Goodin, 1996), buscar maximizar sua autonomia, prestar favores clientelistas para amigos (Cf. Przeworski, 1998a), trabalhar menos tempo, aumentar o orçamento ou até enriquecer (Cf. Przeworski, 1998b).

O clássico problema da assimetria de informações, já apontado por Weber ([1919] 2014) quando de seus estudos sobre a burocracia, se dá porque os promotores detêm expertise e informações que o principal não possui e "podem ter a chance de observar coisas que os principals não podem ver" (Przeworski, 1998b, p. 45). Suas atividades exigem um conhecimento especializado e tempo para se dedicar, além de que, em algumas situações, o "agent tem incentivos para usar essas informações estrategicamente ou simplesmente mantê-las escondidas [...]" (Kiewiet; McCubbins, 1991, p. 25).

Do ponto de vista democrático, é importante identificar se há e quais são os instrumentos institucionais de que o governo dispõe para incentivar determinadas ações e desestimular outras. Afinal, mesmo quando "[...] por uma feliz coincidência, burocratas [leia-se promotores] agem no sentido que os cidadãos desejam que eles ajam, a burocracia pode parecer não ser um problema tão grande, mas não está sob controle democrático" (Gruber, 1987, p. 12). Isso porque

Controle deveria ocorrer por meio de um processo de reações antecipadas. Se os burocratas antecipassem com precisão o que os cidadãos gostariam que fosse feito, e então se sentissem constrangidos a agir baseados nesta antecipação, uma forma de controle democrático teria ocorrido. Mas, se os burocratas estiverem errados na sua antecipação e agirem em um sentido em que os cidadãos e o Legislativo não aprovem, não se pode dizer que suas ações foram controladas pelos cidadãos (Gruber, 1987, p. 12-13).

A tarefa não é tão simples, porque parte desses instrumentos não é facilmente identificável e pode não ser formal, sendo constituída mais de constrangimentos sociais do que incentivos financeiros (Cf. Arrow, 1985). Além disso, o fato de o principal não lançar mão de punições constantemente não significa que não haja um acompanhamento das atividades do agent, mas pode indicar que ele tão somente se adiantou aos desejos de seu principal para evitar punições. Em outras palavras, um dos desafios do pesquisador é identificar se houve uma "delegação" ou uma "abdicação".

Além desse "modelo burocrático" de Ministério Público, existem, pelo menos, outros dois que podem ser analisados sob a perspectiva da independência. Um é o "modelo elei- 
toral" adotado nos Estados Unidos em âmbito local, e o outro é o "modelo independente", encontrado na Itália e no Brasil, que assegura altas doses de autonomia para seus promotores.

Nos estados Unidos, em âmbito local, 45 dos 50 estados escolhem seus promotores, geralmente chamados de district attorney, por meio de eleições diretas. Até os "Secretários de Justiça [State attorneys general], mesmo não sendo considerados promotores no sentido tradicional, também são funcionários eleitos" (Worrall, 2008, p. 4). Assim, o promotor é independente em relação ao governo, mas accountable em relação aos eleitores. O promotor local é o chefe do escritório formado também por funcionários não eleitos. Nesse caso, o principal é o promotor eleito, e os agents são os promotores subordinados e outros funcionários.

Se, para os juízes, há uma dificuldade de se descobrir o que os move ${ }^{16}$ e para o modelo burocrático de Ministério Público, como vimos acima, os interesses podem ser diversos, no caso do modelo eleitoral, aplica-se o axioma da Ciência Política: políticos, assim como promotores locais norte-americanos querem permanecer no poder, e, na democracia, é necessário ser eleito para alcançar esse objetivo. E é aos eleitores que esses promotores prestam contas, ${ }^{17}$ podendo ser premiados ou punidos por sua atuação, o voto $\infty$ accountability, ou pelas promessas em relação

¿ 16 "O mais básico trabalho em modelagem econômica e ¡ psicologia cognitiva demanda conhecimento da 'função

^ utilitária' dos atores relevantes. Por exemplo, quando cien-

$>$ tistas políticos estudam o processo legislativo, eles podem

ธิ operar com alguma noção simples que motiva o parlamen-

tar. Eles querem ser reeleitos e aprovar leis que comportem

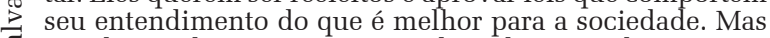

๘ estudiosos do comportamento do Judiciário admitem que

juízes são atores mais complexos e que nós não temos um

tratamento muito bom sobre o que os motiva na perfor-

mance da função judicial” (Burbank; Goldberg, 2002, p. 5).

17 "Promotores locais eleitos, claro, devem responder aos eleitores, mas há numerosas outras fontes de pressão e influência no ambiente" (Worrall, 2008, p. 19). com as mesmas ferramentas da relação entre políticos e burocratas, aqui se empresta o instrumental das análises voltadas para a relação entre eleitores e políticos, a chamada accountability vertical, em que o principal é o eleitor.

Esse modelo tem consequências no sistema judicial. "Os promotores americanos, algumas vezes de forma aberta e sem constrangimento, levam em conta as reações da mídia, a opinião pública e as razões políticas quando decidem a que casos irão dar prosseguimento e como lidarão com eles" (Tonry, 2012, p. 2). Em anos eleitorais, os promotores são mais punitivos, levam mais casos ao júri e dão preferência para os processos de maior repercussão do que nos anos sem eleições (Cf. Tonry, 2012). Ou seja, se o modelo tem a vantagem da accountability direta por parte dos cidadãos, por outro, a utilização de critérios não judiciais é estimulada pela lógica da disputa partidária eleitoral.

O modelo independente, ${ }^{18}$ adotado na Itália e no Brasil, assegura autonomia interna e externa aos promotores, à semelhança daquela prevista para os juízes do Poder Judiciário. No caso italiano, inclusive, promotores e juízes fazem parte da mesma carreira e do mesmo Poder de Estado. Desligados de sua subordinação ao governo após a promulgação das constituições democráticas de ambos os países, como uma espécie de resposta ao período autoritário anterior, os promotores também não se submeteram aos instrumentos de accountability vertical como seus politizados pares norte-americanos. Essa distância de partidos políticos e eleições, paradoxalmente, não afastou os promotores italianos e brasileiros da política, pelo contrário.

De certa forma, as reflexões sobre o paradoxo independência-accountability, que se co-

${ }^{18}$ Nos estados Unidos, entre 1978 e 1999, existiu a figura do promotor independente [Independent Counsel]. Em casos em que fosse necessário investigar e processar o presidente do país ou outros funcionários de alto escalão do governo, um promotor era indicado pelo Congresso e não responderia ao Ministro da Justiça [attorney general]. Depois do escândalo Clinton-Lewinsky, e de debates sobre os riscos de "abuso de poder", o Congresso adotou a figura do Special Counsel que, em última análise, é accountable pelo Ministro da Justiça (Cf. Fleissner, 1987-1988; Johson; Brickman, 2001). 
locam para o Poder Judiciário, e são descritas na primeira parte deste ensaio bibliográfico, podem se aplicar também aos Ministérios Públicos independentes. Contudo, essa independência não pode ser analisada, como no caso do Poder Judiciário, à luz da necessidade histórica de um poder contramajoritário pensado para assegurar direitos da tradição liberal.

Como contrapartida a essa falta de mecanismos formais de accountability, já que os informais existem para qualquer instituição, como foi discutido anteriormente, os sistemas na Itália e no Brasil foram desenhados para que os promotores tivessem baixa discricionariedade. No caso da ação penal, como a mais importante atribuição do Ministério Público, foi adotado o "princípio da legalidade”, em que o promotor deve levar todos os casos apontados pela Polícia ao julgamento do Poder Judiciário. Esse modelo é diferente do "princípio da oportunidade", utilizado nos Estados Unidos e em outros países europeus, em que o promotor pode decidir os casos que devem ser julgados por um juiz a partir de critérios como "interesse público" (Cf. Fionda, 1995). A decisão sobre seguir adiante com um caso é do promotor que, depois, deve responder direta ou indiretamente aos eleitores por suas escolhas.

Essa suposta falta de discricionariedade como substituta da accountability, no entanto, não funciona. "Embora esta distinção conceitual [dos dois princípios] seja inequívoca, empiricamente pode-se observar que promotores, em quase todo lugar, gozam de algum grau de discricionariedade explícita nas suas decisões de indiciar (ou não indiciar)" (Aaken; Feld; Voigt, 2010, p. 217). Nos casos da Itália e do Brasil, essa discricionariedade de facto é observável não somente porque um promotor pode se empenhar mais em um caso do que em outro, por critérios nem sempre muito claros, como, em ambos os países, os promotores passaram a atuar também na investigação criminal. Na Itália, isso foi possível graças à reforma do Código Penal em 1989, em que se atribuiu aos promotores o papel de dirigir a
Polícia na fase de investigação (Cf. Pederzoli; Guarnieri, 1997). No Brasil, essa mudança se formalizou por meio de decisão do Supremo Tribunal Federal brasileiro em 2015, garantindo ao Ministério Público o direito de conduzir investigações criminais, liberando, de forma definitiva, uma prática que já se observava anteriormente (Cf. Kerche, 2014) ${ }^{19}$ Esse poder de conduzir inquéritos penais rompe a divisão de trabalho entre as instituições (Polícia investiga, promotor acusa e juiz julga) e assegura discricionariedade aos promotores ainda na fase de investigação.

Como todas as escolhas institucionais, essas têm suas vantagens e desvantagens. Por um lado, os promotores são mais livres para poder processar políticos em casos de corrupção, por exemplo. ${ }^{20}$ Por outro, a possibilidade de responsabilização dos próprios promotores por suas escolhas é bastante dificultada, para não dizer impossível. O modelo de promotores independentes, incomum para democracias, se baseia mais no "acaso" do que em regras e incentivos institucionais formais típicos da relação entre atores eleitos e não eleitos do Estado. O principal, nesse modelo, seja o cidadão ou o político eleito, somente pode torcer para que seu objetivo coincida com o do agent. Diferentemente dos juízes, essa independência não está ancorada em justificativas históricas ou teóricas do liberalismo e não está limitada pela incapacidade de selecionar os casos que lhe interessam.

${ }^{19}$ Além disso, em 2017, o Conselho Nacional do Ministério Público garantiu discricionariedade aos promotores "para que o MP desista de persecução penal em troca da confissão de suspeitos, em crimes sem violência ou grave ameaça [...], desde que o dano seja inferior a 20 salários mínimos (R\$ 19,5 mil)” (REGRA... 2017). Isso sem falar na discricionariedade do Ministério Público para ações cíveis (Cf. Arantes, 2002).

${ }^{20}$ Estudo envolvendo quase 80 países mostra que, quanto mais as promotorias são independentes de facto, mais baixo é o nível de percepção da corrupção. Por outro lado, quanto mais independente de jure, maior a percepcão de corrupcão, embora a variável não alcance níveis de significância. O trabalho apresenta problemas. Para o Brasil, por exemplo, eles agrupam o Ministério Público de antes e de depois da constituição de 1988, não identificando que os promotores são mais independentes, de jure e de facto, do que na maioria das democracias (Cf. Aaken; Feld; Voigt, 2010). 


\section{CONCLUSÃO}

A defesa da necessidade de independência do Poder Judiciário, embora varie em relação ao grau, é quase um consenso na literatura sobre o tema. A maior parte dos autores defende que juízes sejam mais ou menos protegidos de ingerências externas. Mesmo sendo de difícil justificativa no sistema democrático, baseado, em grande medida, na ideia da accountability, a defesa da independência poderia ser sintetizada como uma espécie de "mal necessário" para assegurar direitos que, caso os juízes se subordinassem à política partidária, seriam provavelmente esmagados por maiorias conjunturais. Por outro lado, contudo, a independência não assegura imparcialidade do juiz e, paradoxalmente, pode inclusive exacerbar o partidarismo e interpretações ideológicas. Mesmo assim, argumentariam os defensores do modelo, o risco da independência seria menor do que aquele que se pagaria no caso de um Poder Judiciário submetido aos desejos dos políticos ou de maiorias na sociedade.

O Ministério Público, por sua vez, embora faça parte do sistema de justiça, normalmente é um órgão do Poder Executivo ou accountable pelos cidadãos. Ao contrário da independência assegurada aos promotores ita-

$\infty$ lianos e brasileiros, na maior parte das demoڤ్ cracias a sociedade pode punir ou premiar, di$\stackrel{\mathcal{J}}{\mathrm{J}}$ reta ou indiretamente, os promotores por suas escolhas e prioridades durante o exercício de क suas funções.

A combinação de um Ministério Público accountable com um Poder Judiciário independente tende a gerar um grau de equilíbrio para as duas instituições. Por um lado, os independentes juízes podem julgar somente o que foi selecionado por um terceiro e, no caso dos promotores, um terceiro accountable politicamente. Por outro lado, o promotor, orientado cisa convencer um Poder de Estado autônomo de seus argumentos.
Já no modelo que combina independência do Judiciário e também do Ministério Público, os riscos de atores não accountable politicamente na democracia podem ser exacerbados. A facilidade do combate à corrupção, sempre apresentada pelos defensores desse modelo como a prova de que ele é o melhor desenho institucional, não esconde que essa tarefa é apenas uma das que devem ser perseguidas pelo sistema de justiça e que mesmo a nobre causa deve observar direitos. O argumento pragmático de que "Se uma instituição está produzindo bons resultados, então ela é uma boa instituição" (Seidman, 1987-1988, p. 1577) não é suficiente na democracia. Esse argumento pragmático também poderia ser utilizado para "boas" ditaduras. Na democracia, resultados positivos são esperados a partir de incentivos gerados, em última instância, pelos cidadãos.

Recebido para publicação em 07 de novembro de 2017 Aceito em 05 de outubro de 2018

\section{REFERÊNCIAS}

AAKEN, A. V.; FELD, L. P.; VOIGT, S. Do independent prosecutor deter political corruption? An empirical evaluation across seventy-eight countries. American law and economics review, v. 12, n. 1, p. 204-244, 2010.

ARANTES, R. B. Ministério público e política no Brasil. São Paulo: Sumaré: Educ, 2002. 327 p.

ARROW, K. The economics of agency. In: PRATT, J.; ZECKHOUSER, R. (Ed.). Principals and agents: the structure of business. Boston: Harvard Business School, 1985. p. 37-51.

BICKEL, A. M. The least dangerous branch: the Supreme Court at the bar of politics. New Haven: Londres: Yale University Press, 1986. 303 p.

BOBBIO, N. Liberalismo e democracia. São Paulo: Brasiliense, 1988. $101 \mathrm{p}$.

BURBANK, S. B. The architecture of judicial independence. Southern California law review, v. 72, p. 315-352, 1999.

; GOLDBERG, D. Introduction. In: FRIEDMAN, B. Judicial independence at the crossroads: an interdisciplinary approach. Thousand Oaks: Nova Deli: Sage Publications, 2002. p. 3-8.

FRIEDMAN, B. Reconsidering judicial independence. In: (Ed.). Judicial independence at the crossroads: an interdisciplinary approach. Thousand Oaks: Nova Deli: Sage Publications, 2002. p. 9-42.

CLARK, T. S. The limits of judicial independence. New York: Cambridge University Press, 2011. 334 p.

CROLEY, S. P. The majoritarian difficulty: elective 
judiciaries and the rule of law. University of Chicago law review, Chicago, v. 62, n. 2, p. 689-794, 1995.

DELGADO, R. Rodrigo's committee assignment: a skeptical look at judicial independence. Southern California law review, v. 72, p. 425-454, 1999.

FEREJOHN, J. Independent judges, dependent judiciary: explaining judicial independence. Southern California law review, v. 72, p. 353-384, 1999.

FIONDA, J. Public prosecutors and discretion: a comparative study. Oxford: Claredon Press, 1995. 288 p.

FLEISSNER, J. P. The future of the independent counsel statute: confronting the dilemma of allocating the power of prosecutorial discretion. Mercer law review, v. 427, p. 427-452, 1997-1998.

GILMAN, H.; CLAYTON, C. The Supreme Court in American politics. Lawrence: University Press of Kansas, 1999. 312 p.

GOODIN, R. E. Institutions and their design. In:

(Ed.). The theory of institutional design. Cambridge: Cambridge University Press, 1996. p. 1-53.

GRUBER, J. E. Controlling bureaucracies. Berkeley: Los Angeles: University of California Press, 1987. 232 p.

GUARNIERI, C. "Judicial independence and policymaking in Italy". In: TATE, N.; VALLINDER, T. (Ed.). The Global expansion of judicial power. Nova York: Londres: NYU Press,1995. p. 243-259.

HARRIGER, K. J. Independent justice: the federal special prosecutor in American politics. Lawrence: University Press of Kansas, 1992. 276 p.

JOHSON, C. A.: BRICKMAN, D. Independent counsel: the law and the investigations. Washington: CQ Press, 2001. $356 \mathrm{p}$

KERCHE, F. Virtude e limites: autonomia e atribuições do Ministério Público no Brasil. São Paulo: Edusp. 2009. 118 p.

O Ministério Público no Brasil: relevância, características e uma agenda para o futuro. Revista da $U S P$, v. 101, p. 114-120, 2014.

KIEWIET, D. R.; McCUBBINS, M. The logic of delegation: congressional parties and the appropiations process. Chicago: University of Chicago Press, 1991. 299 p.

LINZER, D. A.; STATON, J. K. A global measure of judicial Independence, 1948-2012. Journal of Law and Courts, fall, p. 223-256, 2015.

MADISON, J.; HAMILTON, A.; JAY, J. Os artigos federalistas. $1^{\mathrm{a}}$ edição [1788]. Rio de Janeiro: Nova Fronteira, 1993. 534 p

MANIN, B.; PRZEWORSKI, A.; STOKES, S. C. Elections and Representation. In: PRZEWORSKI, A.; STOKES, S. C. MANIN, B. Democracy, accountability and representation. Cambridge: Cambridge University Press, 1999. p. 29-54.

MARAVALL, J. M. The rule of law as a political weapon. In: _ PRZEWORSKI, A. (Ed.). Democracy and the rule of law. Cambridge: Cambridge University Press, 2003. p. 261-301.

McCUBBINS, M.; NOBLE, G. Equilibrium behavior and the appearance of power: legislators, bureaucrats and the budget process in the U.S. and Japan. In: COWHEY, P.; $\quad$ (Ed.). Structure and policy in Japan and the United States. Nova York: Cambridge University Press, 1995. p. 56-80.

MELTON, J; GINSBURG, T. Does de jure judicial independence really matter? Journal of Law and Courts, fall, p. 187-217, 2014.

MOE, T. M. The new economics of organization. American journal of political science, v. 28, n. 4, p. 739-777, 1984.

MONTESQUIEU. Do espírito das leis. $1^{\circ}$ edição [1748]. São Paulo: Abril Cultural, 1973. 569 p.
PEDERZOLI, P.; GUARNIERI, C. The judicialization of politics, Italian style. Journal of modern Italian studies, v. 2, n. 3, p. 321-336, 1997.

PETERS, G. B. Institutional theory in political science. Nova York: Continuum, 2012. 222 p.

PRZEWORSKI, A. The state and the citizen. In: SEMINÁRIO SOCIETY AND THE REFORM OF THE STATE, 1998, São Paulo. Proceedings... São Paulo: [S.n.], $1998 \mathrm{a}$

Sobre o desenho do Estado: uma perspectiva agent x principal. In: BRESSER-PEREIRA, L. C.; SPINK, P. (Org.) Reforma do Estado e administração pública gerencial. Rio de Janeiro: Editora Fundação Getúlio Vargas, 1998b. p. 3974.

REGRA que permite ao MP ignorar açãopenal gera controvérsias. Revista Consultor Jurídico, set. 2017. Disponível em: <https://www.conjur.com.br/2017set-11/regra-permite-mp-ignorar-acao-penal-geracontroversias > . Acesso em: 11 set. 2017

RUSSELL, P. H. Toward a general theory of judicial independence. In: ; O'BRIEN, D. M. Judicial independence in the age of democracy: critical perspectives from around the world. Charlottesville: Londres: University of Virginia, 2001. p. 1-24.

SEIDMAN, L. M. Ambivalence and Accountability. Southern California law review, v. 61, p. 1571-1600, 19871988

SHAPIRO, M. Judicial independence: new challenges in stablished nations. Indiana Journal of global legal studies, v. 20 , n. 1, p. 253-277, 2013.

SUTHERLAND, S. L. Independent review and politica accountability: should democracy be on autopilot. Optimum: Journal of public sector management, v. 24, p. 23-41, 1993

TAYLOR. M. M. O Judiciário e as políticas públicas no Brasil. Dados, Rio de Janeiro, v. 50, n. 2, p. 229-257, 2007.

TONRY, M. (Ed.). Prosecutors and politics. Chicago: Londres: The University of Chicago Press, 2012. 366 p.

WEBER, M. A política como profissão e vocação. In: Escritos políticos. $1^{\circ}$ edição [1919]. São Paulo: Martins Fontes, 2014. p. 389-463.

WEST, F. W. Controlling the bureaucracy. Armonk: Londres: M.E. Sharp, 1995. 219 p.

WORRALL, J. L. Prosecution in America: a historical and comparative account. In: M. E. The changing role of the American prosecutor Albany: State University Press, 2008. p. 3-27. 


\section{INDEPENDENCE, JUDICIARY AND PUBLIC PROSECUTOR'S OFFICE}

\section{Fábio Kerche}

Academic studies on the issue of the Judiciary and judges' independence, both normatively and descriptively, are reasonably developed. The current academic production is significant and discusses both the dilemmas and difficulties of there being a branch of the government with high doses of autonomy in democratic regimes. From the democratic point of view, the issue is how barely-accountable actors coexist in a system based fundamentally on citizens' vote. In relation to this debate, less attention is given to the Public Prosecutor's Office and the prosecutors. This bibliographic essay analyzes, synthesizes and reinterprets part of the academic production on independence and its tensions in democracy in relation to the Judiciary and also presents a proposal of how to study the same subject in the Public Prosecutor's Office.

Keywords: Judiciary. Public Prosecutor's Office. Independency. Democracy.

\section{INDÉPENDANCE, POUVOIR JUDICIAIRE ET MINISTÈRE PUBLIC}

\section{Fábio Kerche}

Les études académiques sur la question de l'indépendance du Judiciaire et des juges, tant sur le plan normatif que sur le plan descriptif, sont raisonnablement développés. La production est significative et discute les dilemmes et les difficultés de l'existence d'un pouvoir d'Etat avec de fortes doses d'autonomie dans les régimes démocratiques. Du point de vue de la démocratie, la question est de savoir comment des acteurs si peu responsables coexistent dans un système basé fondamentalement sur le vote des citoyens. Moins d'attention est accordée au Ministère Public et aux procureurs en ce qui concerne ce débat. Cet essai bibliographique analyse, synthétise et réinterprète une partie de la production académique sur l'indépendance et ses tensions dans la démocratie par rapport à la magistrature et présente une proposition sur la façon d'étudier le même sujet par rapport au Ministère Public.

Mots CLÉs: Judiciaire. Ministère Public. Indépendance. Démocratie. pesquisador associado na American University. Publicações recentes: Operação Lava Jato e a democracia brasileira (Org.). São Paulo, Ed. Contracorrente, 2018); Virtude e Limites: autonomia e atribuições do Ministério Público no Brasil (São Paulo, Edusp, 2009). 